\title{
Physiological changes of three woody plants exposed to progressive salt stress
}

\author{
Y. LU $U^{*, * * * * *,+}$ (iD) , F.J. ZENG ${ }^{*, * * * * *,+}$, X.Y. LI $^{*, * * * * *}$, and B. ZHANG ${ }^{*, * * * * * *}$
}

Xinjiang Key Laboratory of Desert Plant Roots Ecology and Vegetation Restoration, Xinjiang Institute of Ecology and Geography, Chinese Academy of Sciences, 830011 Urumqi, China*

State Key Laboratory of Desert and Oasis Ecology, Xinjiang Institute of Ecology and Geography, Chinese Academy of Sciences, 830011 Urumqi, China ${ }^{* *}$

Cele National Station of Observation and Research for Desert-Grassland Ecosystems, 848300 Cele, China***

\begin{abstract}
The saline character of water imposes restrictions on plant growth and survival in the Taklamakan Desert, China. Experiments were conducted on woody plant species, Tamarix ramosissima, Populus euphratica, and Haloxylon ammodendron grown under different levels of salinity to elucidate their adaptation to a saline environment. $H$. ammodendron accumulated large amounts of $\mathrm{Na}^{+}$and $\mathrm{Cl}^{-}$in leaves. $P$. euphratica restricted redundant $\mathrm{Na}^{+}$and $\mathrm{Cl}^{-}$transport to the shoots treated with lower $\mathrm{NaCl}$ concentrations. $\mathrm{Na}^{+}$in leaves of $T$. ramosissima accumulated significantly only under higher $\mathrm{NaCl}$ concentrations $(\geq 200 \mathrm{mM} \mathrm{NaCl}$ ). The analyzed plants' exposure to high saline concentrations induced oxidative stress as evidenced by the increase of $\mathrm{H}_{2} \mathrm{O}_{2}$ and malondialdehyde and changes in photosynthetic pigments, gas-exchange characteristics, and antioxidant enzyme activities. T. ramosissima and H. ammodendron exhibited a greater ability to adapt to saline-induced oxidative stress due to more efficient antioxidant enzyme system to prevent oxidative damage.
\end{abstract}

Keywords: antioxidative defense; osmotic adjustment; photosynthesis; water relations.

\section{Introduction}

Soil salinization is a major international concern and more than $6 \%$ of the world's land suffers from salinity (FAO and ITPS 2015). In China, nearly 35 million hectares have been saline (Pan et al. 2013). Soil salinity problem is a major problem for ecology and agriculture worldwide, particularly in arid and semiarid regions, where soil water availability is low, evaporation is high, and precipitation is deficient in terms of salt leaching (Cui et al. 2011). Soil degradation resulting from various types of salinity is a major environmental problem, especially in arid and semiarid regions (Min et al. 2019). Plants are very sensitive to abiotic stresses, including salinity (Sehar et al.

\section{Highlights}

- Changes in photosynthetic parameters differed between species exposed to salinity

- The higher oxidative damage was reported in Populus euphratica

- More effective ROS scavenging was observed in Haloxylon ammodendron and Tamarix ramosissima
Received 5 November 2020

Accepted 20 January 2021

Published online 26 February 2021

${ }^{+}$Corresponding author

e-mail: zengfj@ms.xjb.ac.cn (F.J. Zeng)

luyanu@126.com (Y. Lu)

Abbreviations: APX - ascorbate peroxidase; CAT - catalase; $\mathrm{Car}$ - carotenoids; $\mathrm{Chl}$ - chlorophyll; $C_{\mathrm{i}}$ - intercellular $\mathrm{CO}_{2}$ concentration; $\mathrm{DM}$ - dry mass; $E$ - transpiration rate; FM - fresh mass; $g_{\mathrm{s}}$ - stomatal conductance; MDA - malondialdehyde content; $P_{\mathrm{N}}-$ net photosynthetic rate; POD - guaiacol peroxidase; ROS - reactive oxygen species; RWC - relative water content; SOD - superoxide dismutase; WUE - water-use efficiency; $\psi_{\mathrm{w}}$ - water potential.

Acknowledgments: This work was financially supported by Poverty Alleviation Program of Chinese Academy of Sciences (KFJFP-201903), National Natural Science Foundation of China (41977050), and Key Program of Joint Funds of the National Natural Science Foundation of China and the Government of Xinjiang Uygur Autonomous Region of China (U1603233, U1903102).

Conflict of interest: The authors declare that they have no conflict of interest. 
2019, Rajhi et al. 2020). Therefore, in order to meet the demand for rehabilitation of degraded arid lands, a detailed understanding of the mechanisms employed by plants in adaptation to salt stress is of a high priority for land utilization.

Salinity influences almost every aspect of physiology and biochemistry of plants, and therefore significantly limits plant growth and productivity. Plants cope with salinity in two ways; first, additional accumulation of $\mathrm{Na}^{+}$in root results in osmotic stress, which reduces water potential, and secondly damage to nutrient balance leads to ionic stress (Munns 2005). $\mathrm{Na}^{+}$being a nonessential mineral nutrient for most of the plants gets accumulated in plant tissues under saline environment, therefore, changes in ratios of $\mathrm{Na}^{+} / \mathrm{Ca}^{2+}, \mathrm{Na}^{+} / \mathrm{K}^{+}, \mathrm{Na}^{+} / \mathrm{Mg}^{2+}$, and $\mathrm{Cl}^{-} /$ $\mathrm{NO}^{3-}$, thus affect plant growth and productivity (Singh et al. 2014, Sofy et al. 2020). Furthermore, excessive salt accumulation changes electron transport systems occurring in the chloroplast, mitochondria, and plasma membranes resulting in the formation of reactive oxygen species (ROS) as byproducts of oxygen metabolism (Singh et al. 2015). Especially, salinity-evoked inhibition of the photosynthetic electron transport causes overaccumulation of toxic ROS, such as superoxide radical $\left(\mathrm{O}_{2}{ }^{-}\right)$, hydroxyl radical $\left({ }^{\circ} \mathrm{HO}\right)$, and hydrogen peroxide $\left(\mathrm{H}_{2} \mathrm{O}_{2}\right)$. Excessive accumulation of ROS induces degradation of chlorophyll (Chl) and decreases photochemical efficiency of PSII developing a vicious cycle (Allakhverdiev et al. 2008). ROS is also able to promote oxidative damage to many cellular constituents, such as membrane lipids, proteins, and nucleic acids (Mittler 2002, Gechev and Petrov 2020). One of the most negative effects of oxidative damage is the peroxidation of membrane lipids, which results in the accompanying production of malondialdehyde (MDA) (Lu et al. 2017, López-Serrano et al. 2020). In order to regulate the content of ROS, plants employ a well-formed and complicated antioxidant defense system including enzymatic and nonenzymatic antioxidant processes (Blokhina et al. 2003, Asrar et al. 2020). The antioxidant enzymes involve superoxide dismutases (SOD, EC 1.15.1.1), catalases (CAT, EC 1.11.1.6), guaiacol peroxidase (POD, EC 1.11.1.7), and ascorbate peroxidase (APX, EC 1.11.1.11), which can clean and/or neutralize ROS (Blokhina et al. 2003, Rattan et al. 2020).

The Taklamakan Desert in Northwest China has one of the world's most extreme environmental habitats for plants. The natural vegetation is distinguished by sparse coverage, low diversity, and dominated by perennial plant species (Arndt et al. 2004). The available water resource is groundwater that can reach the surface and be recharged by snowmelt water from the Tian-Shan and Kunlun ranges (Shi et al. 1989). All surficial waters in the Taklamakan have high $\mathrm{pH}$ and are rich in sulfate and sodium chloride (Gibert et al. 1996). Hence, it is an adverse environment in which merely a few perennial plant species can settle and grow (Arndt et al. 2004). Accordingly, the physiology of the vegetation that allows thriving under extremely hostile conditions should be studied. Tamarix ramosissima and Populus euphratica, two perennial woody species, are native to the Cele river oases at the extremely arid south rim of the Taklamakan Desert. In recent years, Haloxylon ammodendron, a perennial woody species, is introduced in the south rim of the Taklamakan Desert as an excellent economic sand-fixing species, owing to its high endurance to saline-alkaline and drought (Fan et al. 2018) and being taken as the host of medicinal plant Cistanche. In this study, we analyzed the effects of progressively increased salinity exposure on $H$. ammodendron, T. ramosissima, and $P$. euphratica. This study aimed to (1) determine ion concentrations $\left(\mathrm{Na}^{+}, \mathrm{K}^{+}, \mathrm{Ca}^{2+}, \mathrm{Mg}^{2+}\right.$, and $\left.\mathrm{Cl}^{-}\right)$in leaves, stems, and roots of the three species; (2) compare the distribution of ion concentrations among the three species; (3) evaluate the stress caused by salinity and the capacity of endurance and detoxification employed by measuring photosynthetic pigments, gas-exchange characteristics, water status, compatible solutes, membrane injury, and enzymatic antioxidant system; and (4) elucidate the relationships among all tested physiological and biochemical parameters and evaluate which parameters can be used as valuable screening criteria for the improvement and selection of salt tolerance. Consequently, the results from this study could not only help estimate the suitability of the three species for revegetation of salt-influenced soils but also for choosing the suitable physiological and biochemical parameters as screening criteria.

\section{Materials and methods}

Plant materials and experimental treatments: A pot experiment was conducted from 15 April to 25 August 2011 at the site of the Cele Research Station of the Xinjiang Institute of Ecology and Geography, Chinese Academy of Sciences, located in the Cele Oasis $\left(80^{\circ} 03^{\prime} 24^{\prime \prime}-\right.$ $82^{\circ} 10^{\prime} 34^{\prime \prime} \mathrm{E} ; 35^{\circ} 17^{\prime} 55^{\prime \prime}-39^{\circ} 30^{\prime} 00^{\prime \prime} \mathrm{N} ; 1340-1380 \mathrm{~m}$ a.s.1.). During the experiment, the precipitation was only $5.6 \mathrm{~mm}$, the temperature ranged from 10 to $40^{\circ} \mathrm{C}$ by day and 5 to $20^{\circ} \mathrm{C}$ by night, and the relative humidity $(\mathrm{RH})$ varied from 20 to $60 \%$, maximum values of PAR rarely exceeded 1,600 $\mu \mathrm{mol}$ (photon) $\mathrm{m}^{-2} \mathrm{~s}^{-1}$ (Zeng et al. 2006). T. ramosissima cut seedlings, one-year-old $H$. ammodendron, and $P$. euphratica seedlings, with an initial height of 25,35 , and $55 \mathrm{~cm}$, respectively for each plant species, were planted on 15 April into plastic pots (diameter of $50 \mathrm{~cm}$, height of $42 \mathrm{~cm}$ ) filled with $30 \mathrm{~kg}$ of soil from a desertoasis ecotone (sampling depth of $0-30 \mathrm{~cm}$ ) and previously passed through a sieve of $2 \mathrm{~mm}$. Soil characteristics were shown by Lu et al. (2017). In order to prevent plants from being hurt by extremely high temperatures, all of the pots were embedded underground.

Forty days after transplanting, salinity growth environments were simulated by adding $\mathrm{NaCl}$ to deionized water at five concentrations $(0,50,100,200$, and $400 \mathrm{mM})$. To avoid saline shock, the $\mathrm{NaCl}$ was applied stepwise in aliquots of $50 \mathrm{mM}$ daily till the final concentrations were accomplished. After $90 \mathrm{~d}$, plants were ready for analysis.

Ion concentration: Four individual plants for each treatment were cleaned in deionized water, and rinsed three times with deionized water. After washing, plants were separated into leaves, stems, and roots, and dried in an 
oven at $70^{\circ} \mathrm{C}$ for $72 \mathrm{~h}$. Then the dried materials were ashed in a muffle furnace at $550^{\circ} \mathrm{C}$ for $24 \mathrm{~h}$. The ash $(0.1 \mathrm{~g})$ was digested overnight with $25 \mathrm{ml}$ of $0.1 \mathrm{M} \mathrm{HNO}_{3}$ (Sibole et al. 2003). Concentrations of $\mathrm{Na}^{+}, \mathrm{K}^{+}, \mathrm{Ca}^{2+}$, and $\mathrm{Mg}^{2+}$ in the acid extract were measured by an inductively coupled plasma-optical emission spectrometer (ICP-OES, Agilent 735, Santa Clara, CA, USA), and the $\mathrm{Cl}^{-}$content was detected using the same extract by a chloride meter (Jenway PC LM3, London, UK).

Photosynthetic pigment and gas-exchange characteristics: Photosynthetic pigments were extracted by $80 \%$ acetone. The clear supernatant fraction obtained after centrifugation at $480 \times g$ for 3 min was employed for determination, using the extinction coefficients and equations redetermined by Lichtenthaler (1987).

Net photosynthetic rate $\left(P_{\mathrm{N}}\right)$, transpiration rate $(E)$, stomatal conductance $\left(g_{\mathrm{s}}\right)$, and intercellular $\mathrm{CO}_{2}$ concentration $\left(C_{\mathrm{i}}\right)$ were measured by a portable photosynthesis system (LI-6400, LI-COR, Lincoln, NE, USA) between 10:30 and 11:00 h. Four plants were chosen for each treatment under the following atmospheric conditions: PAR of $1,279 \pm 57 \mu \mathrm{mol}$ (photon) $\mathrm{m}^{-2} \mathrm{~s}^{-1}, \mathrm{CO}_{2}$ concentration of $384.5 \pm 4.7 \mu \mathrm{mol} \mathrm{mol}{ }^{-1}$, temperature of $29.6 \pm 1.3^{\circ} \mathrm{C}$, $\mathrm{RH}$ of $33.1 \pm 1.2 \%$. Water-use efficiency (WUE) was calculated as the ratio of $P_{\mathrm{N}}$ to $E$. Due to the irregular shape of $T$. ramosissima leaves, after photosynthetic measurement, the irregular leaves in the chamber were removed and carefully spread and scanned, the scanned images were processed, and the surface area of leaves calculated using the image analysis system Delta-T Scan (Cambridge, UK), and gas-exchange parameters were recalculated according to the actual effective photosynthetic area.

RWC and $\psi_{\mathrm{w}}$ : RWC was calculated according to Smart and Bingham (1974) and was obtained by the following formula: $\mathrm{RWC}=(\mathrm{FM}-\mathrm{DM}) /(\mathrm{TM}-\mathrm{DM}) \times 100 \%$. Turgid mass (TM) was measured after floating leaves in distilled water for $4 \mathrm{~h}$ at room temperature in darkness. Leaf $\psi_{\mathrm{w}}$ was detected on freshly cut leaves using a WP4 dewpoint water potential meter (Decagon Devices, Inc., Pullman, WA, USA).

Total soluble sugars and proline contents: The content of soluble sugars was determined by the anthrone method (Palma et al. 2009). The proline content was measured according to the method of Bates et al. (1973) using a spectrophotometer (UV752 N, Shanghai Precision \& Scientific Instrument Co., Ltd., China).

MDA and $\mathrm{H}_{2} \mathrm{O}_{2}$ content: MDA content was measured based on the method of Kosugi and Kikugawa (1985). $\mathrm{H}_{2} \mathrm{O}_{2}$ concentration was determined according to the method of Sergiev et al. (1997) using a spectrophotometer (UV752 N, Shanghai Precision \& Scientific Instrument Co., Ltd., China).

Enzyme extraction and assays: The supernatant fraction adopted for determining soluble protein content and SOD,
POD, CAT, and APX activities was acquired by the method of Lu et al. (2010). Enzyme activities were measured using a spectrophotometer (UV752 N, Shanghai Precision \& Scientific Instrument Co., Ltd., China). SOD (EC 1.15.1.1) activity was measured according to the method of Beauchamp and Fridovich (1971). CAT (EC 1.11.1.6) activity was assayed by detecting the consumption of $\mathrm{H}_{2} \mathrm{O}_{2}$ by the method of Aebi (1984). POD (EC 1.11.1.7) activity was obtained based on the method of Chance and Maehly (1955). APX (EC 1.11.1.11) activity was measured by the method of Nakano and Asada (1981).

Proteins were measured according to the method of Bradford (1976) taking bovine serum albumin as the standard protein.

Statistical analysis: Four independent experiments were carried out to evaluate the effects of $\mathrm{NaCl}$ treatments on selected physiological and biochemical indexes. Data presented here are means $\pm \mathrm{SD}$. Mean values were separated using Tukey's tests at the 0.05 probability level. A linear regression analysis was employed to analyze the relationship between $\mathrm{NaCl}$ content and detected parameters at different salinity levels. The analysis was performed with SPSS Inc., version 13 (Chicago, USA). To acquire a multivariable view of tested parameters and the three species at all salinity concentrations, and also the interrelationships between tested parameters, the mean values of salt-tolerance coefficient of selected physiological and biochemical parameters for the three species and four salinity concentrations were exposed to principal component analysis (PCA). The salt-tolerance coefficient was calculated using the following formula: salt-tolerance coefficient $=$ (mean value under different salinity concentrations/mean value under control) $\times 100 \%$. The PCA was carried out according to correlation matrix data.

\section{Results}

Ion concentrations: In general, as the salinity concentration elevated, the content of toxic ions $\left(\mathrm{Na}^{+}\right.$and $\left.\mathrm{Cl}^{-}\right)$ also increased in the three species. Toxic ions in leaves of $H$. ammodendron and $P$. euphratica increased more dramatically compared to $T$. ramosissima (Fig. 1). $\mathrm{Na}^{+}$in leaves of $H$. ammodendron and $P$. euphratica was elevated by 56.2 and $183.9 \%$ at the highest $\mathrm{NaCl}$ treatment compared to control, however, it increased only $29.2 \%$ in leaves of T. ramosissima (Fig. $1 A-C$ ). Similarly, $\mathrm{Cl}^{-}$in leaves of H. ammodendron and P. euphratica increased by 140.1 and $78.1 \%$ at the highest $\mathrm{NaCl}$ treatment compared to control, respectively, however, it was elevated only by $30.4 \%$ in leaves of T. ramosissima (Fig. $1 M-O$ ). $\mathrm{Na}^{+}$and $\mathrm{Cl}^{-}$ accumulated most in leaves of the three species, especially for $H$. ammodendron, in which $\mathrm{Na}^{+}$and $\mathrm{Cl}^{-}$concentrations in leaves were 8 and 4 times higher than that in roots under $400 \mathrm{mM} \mathrm{NaCl}$ treatment. None remarkable effects of $\mathrm{NaCl}$ were observed for $\mathrm{Ca}^{2+}$ and $\mathrm{Mg}^{2+}$ concentrations (Fig. $1 G-L$ ), however, $\mathrm{K}^{+}$contents prominently increased in roots of $T$. ramosissima and significantly decreased in roots of $P$. euphratica (Fig. 1E,F). 


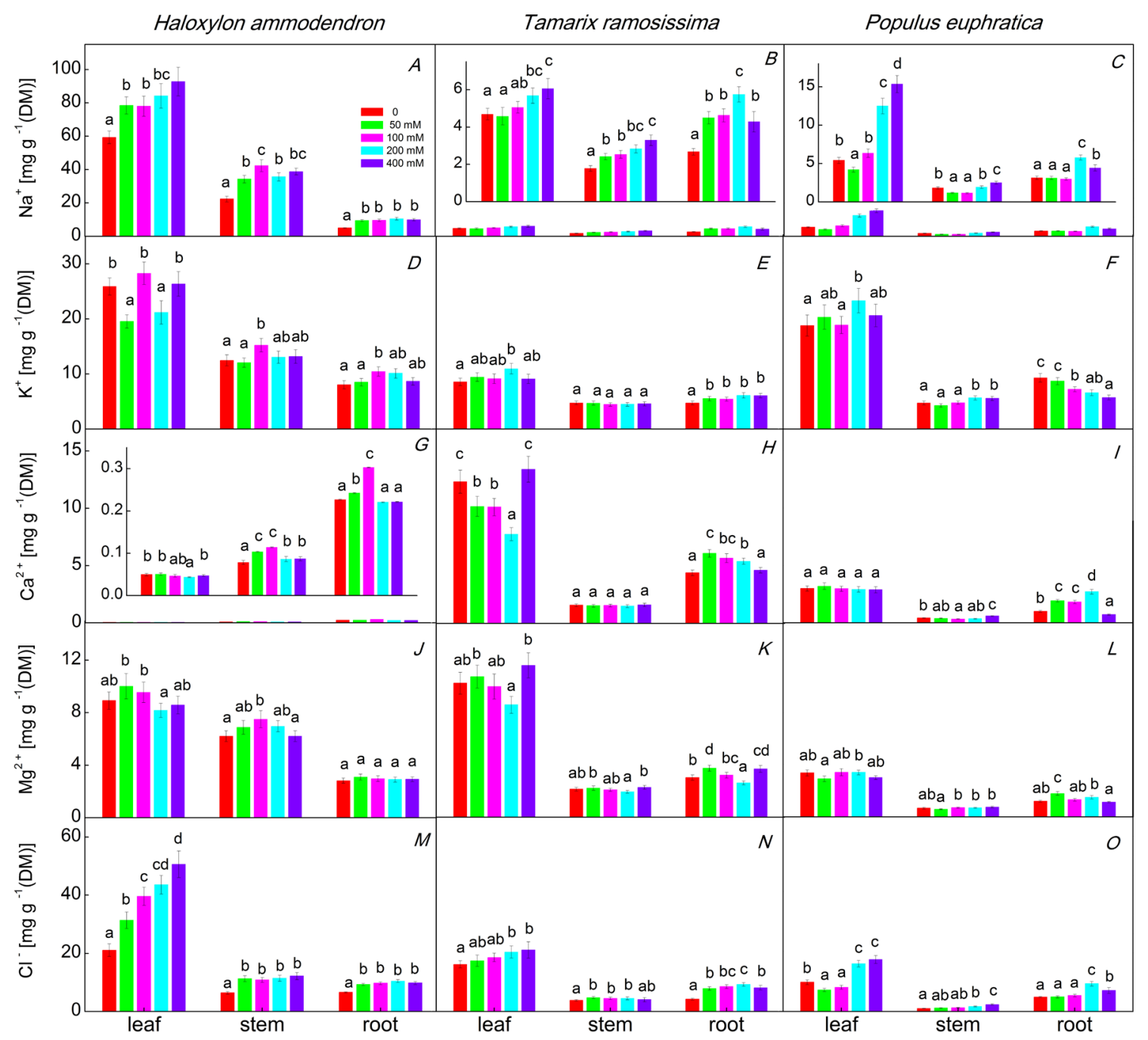

Fig. 1. Effects of $\mathrm{NaCl}$ exposure $(0,50,100,200$, and $400 \mathrm{mM})$ on $\mathrm{Na}^{+}(A-), \mathrm{K}^{+}(D-F), \mathrm{Ca}^{2+}(G-I), \mathrm{Mg}^{2+}(J-L)$, and $\mathrm{Cl}^{-}(M-O)$ contents in leaves, stems, and roots of Haloxylon ammodendron, Tamarix ramosissima, and Populus euphratica. Values are means $\pm \mathrm{SD}(n=4)$. Different lowercase letters indicate significant differences of ion contents in the same organ across the range of $\mathrm{NaCl}$ concentrations at $p<0.05$ according to Fisher's LSD test.

$\mathrm{Na}^{+} / \mathrm{Ca}^{2+}, \mathrm{Na}^{+} / \mathrm{K}^{+}$, and $\mathrm{Na}^{+} / \mathrm{Mg}^{2+}$ ratios are often used to represent the degree of salt injury in plants. In general, the ratios in leaves, stems, and roots of the three species increased with increasing $\mathrm{NaCl}$ concentrations, and the ratios were substantially greater in $H$. ammodendron than that in $T$. ramosissima and $P$. euphratica (Fig. 1S, supplement).

Photosynthetic pigments: Chl $a, b,(a+b)$, and carotenoid (Car) content reached the peak value in leaves of the three species under $50 \mathrm{mM} \mathrm{NaCl}$ treatment and gradually declined with the increasing $\mathrm{NaCl}$ concentration (Fig. 2). The significant decrease of $\mathrm{Chl} a, b,(a+b)$, and Car were detected at $200 \mathrm{mM} \mathrm{NaCl}$ in leaves of $H$. ammodendron (Fig. $2 A, D, G, J$ ), the significant reduction in $\mathrm{Chl} b$ and Car were measured at $200 \mathrm{mM} \mathrm{NaCl}$ in leaves of $T$. ramosissima (Fig. 2E,K); for $\mathrm{Chl} a$ and Chl $(a+b)$, significant reductions were observed at 400
$\mathrm{mM} \mathrm{NaCl}$ (Fig. 2B,H), however, the marked decrease of Chl $a, b,(a+b)$, and Car was measured at 100 $\mathrm{mM} \mathrm{NaCl}$ in leaves of $P$. euphratica (Fig. 2C,F,I,L). Chl $(a+b)$ content in leaves of $H$. ammodendron, T. ramosissima, and $P$. euphratica was reduced by 27.4 , 8.7 , and $62.1 \%$ at the highest $\mathrm{NaCl}$ treatment, respectively, and the Car content decreased by $35.1,18.3$, and $74.9 \%$, respectively. The $\mathrm{Chl} a / b$ ratio in leaves of $T$. ramosissima was not influenced by $\mathrm{NaCl}$ addition (Fig. $2 \mathrm{~N}$ ); it was reduced in leaves of $H$. ammodendron at higher $\mathrm{NaCl}$ treatment (Fig. 2M), however, it increased in leaves of $P$. euphratica at higher $\mathrm{NaCl}$ treatment (Fig. 2O). The $\mathrm{Car} / \mathrm{Chl}$ ratio declined with elevated $\mathrm{NaCl}$ concentrations, a significant decrease in leaves of $H$. ammodendron, T. ramosissima, and $P$. euphratica was observed at 400, 200, and $100 \mathrm{mM} \mathrm{NaCl}$, respectively (Fig. 2P-R).

Gas-exchange characteristics: The three species treated 




Fig. 2. Effects of $\mathrm{NaCl}$ exposure $(0,50,100$, 200 , and $400 \mathrm{mM})$ on Chl $a(A-C), \mathrm{Chl} b(D-F)$, Chl $(a+b)(G-I)$, Car $(J-L)$, Chl a/b $(M-O)$, and $\mathrm{Chl} / \mathrm{Car}(P-R)$ in leaves of Haloxylon ammodendron, Tamarix ramosissima, and Populus euphratica. Values are means \pm SD $(n=4)$. Different lowercase letters indicate significant differences at $p<0.05$ according to Fisher's LSD test. with $50 \mathrm{mM} \mathrm{NaCl}$ reached maximal values for $P_{\mathrm{N}}, E$, and $g_{\mathrm{s}}$ (Fig. 3). However, increasing salinity stress $(\geq 100 \mathrm{mM}$ $\mathrm{NaCl})$ resulted in a progressive decrease in $P_{\mathrm{N}}, E$, and $g_{\text {s }}$ compared with the control. The significant reduction in leaves of $H$. ammodendron and $T$. ramosissima was detected at $200 \mathrm{mM} \mathrm{NaCl}$ addition (Fig. $3 A, B, D, E, G, H$ ), while the significant reduction in leaves of $P$. euphratica was detected at $100 \mathrm{mM} \mathrm{NaCl}$ addition (Fig. 3C,F,I). $C_{\mathrm{i}}$ in leaves of $H$. ammodendron and $P$. euphratica increased with increasing $\mathrm{NaCl}$ concentration (Fig. $3 J, L$ ), however, it was not affected initially in leaves of $T$. ramosissima, while a significant increase was observed at $400 \mathrm{mM}$ $\mathrm{NaCl}$ (Fig. $3 \mathrm{~K}$ ). Under higher $\mathrm{NaCl}$ treatment $(\geq 100 \mathrm{mM}$ $\mathrm{NaCl}$ ), WUE in leaves of three species was promoted (Fig. $3 M, N, O)$.

RWC and $\psi_{\mathrm{w}}$ : RWC in leaves of the three species was not affected under $50 \mathrm{mM} \mathrm{NaCl}$ concentration (Fig. 4A-C). Then it increased significantly in leaves of $\mathrm{H}$. ammo- dendron with increasing $\mathrm{NaCl}$ concentration $(\geq 100 \mathrm{mM}$ $\mathrm{NaCl}$ ) (Fig. 4A). In leaves of T. ramosissima, it decreased progressively with increasing $\mathrm{NaCl}$ exposure (Fig. 4B), and it initially decreased, and then it increased but still maintained at control level in leaves of $P$. euphratica (Fig. 4C).

Leaf $\psi_{\mathrm{w}}$ of the three species was remarkably affected by $\mathrm{NaCl}$ exposure, decreasing significantly with increasing $\mathrm{NaCl}$ concentration $\left(R_{H . \text { ammodendron }}=-0.992 ; R_{\text {T. ramosissima }}=\right.$ $\left.-0.984 ; R_{P \text {. euphratica }}=-0.979, P<0.01\right)$, it was reduced by $18.9-60.2 \%, 24.2-104.7 \%$, and $14.2-97.3 \%$ in leaves of $H$. ammodendron, T. ramosissima, and $P$. euphratica, respectively, with elevated $\mathrm{NaCl}$ content compared to control (Fig. 4D-F).

Total soluble sugars and proline content: Proline in leaves of $H$. ammodendron was increasing with increasing $\mathrm{NaCl}$ concentration $(R=0.981, P<0.01)$ (Fig. $5 A)$, it initially increased and reached the peak value at 100 


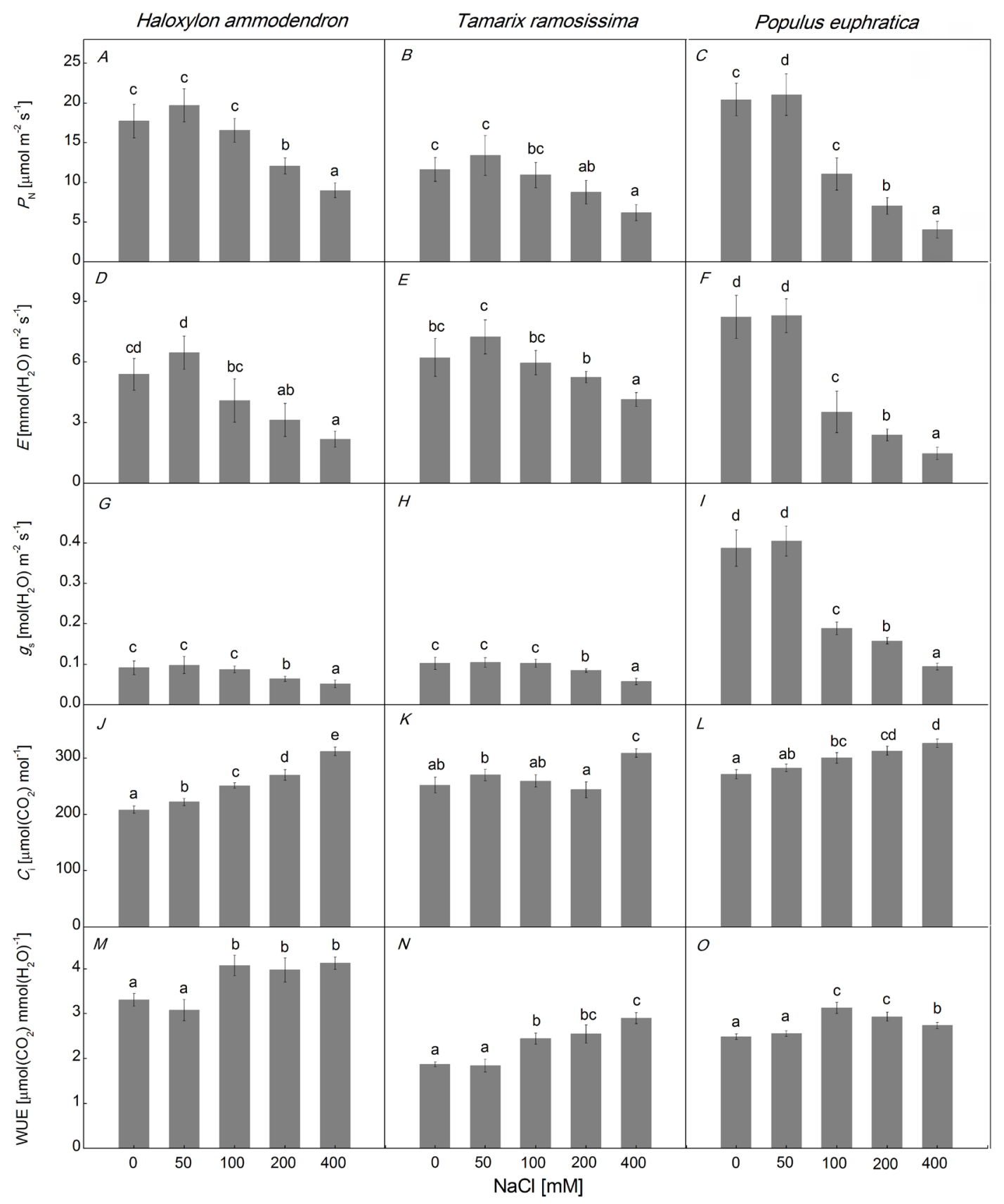

Fig. 3. Effects of $\mathrm{NaCl}$ exposure $(0,50,100,200$, and $400 \mathrm{mM})$ on net photosynthetic rate $\left(P_{\mathrm{N}}\right)(A-C)$, transpiration rate $(E)(D-F)$, stomatal conductance $\left(g_{\mathrm{s}}\right)(G-I)$, intercellular $\mathrm{CO}_{2}$ concentration $\left(C_{\mathrm{i}}\right)(J-L)$, and water-use efficiency (WUE) $(M-O)$ in leaves of Haloxylon ammodendron, Tamarix ramosissima, and Populus euphratica. Values are means \pm SD $(n=4)$. Different lowercase letters indicate significant differences at $p<0.05$ according to Fisher's LSD test.

and $50 \mathrm{mM} \mathrm{NaCl}$ in leaves of $T$. ramosissima and $P$. euphratica, respectively, and began to decrease but still maintained at control level even at the highest $\mathrm{NaCl}$ concentration (Fig. 5B,C).

Soluble sugar in leaves of $H$. ammodendron and T. ramosissima initially increased with increasing $\mathrm{NaCl}$ concentration and reached the peak value at $200 \mathrm{mM} \mathrm{NaCl}$, however, it began declining significantly at $400 \mathrm{mM} \mathrm{NaCl}$ compared with control (Fig. 5D,E). It was significantly influenced by $\mathrm{NaCl}$ exposure in leaves of $P$. euphratica, decreasing with elevated $\mathrm{NaCl}$ concentrations $(R=-0.888$, $P<0.05$ ) (Fig. 5F).

MDA and $\mathrm{H}_{2} \mathrm{O}_{2}$ content: In general, $\mathrm{H}_{2} \mathrm{O}_{2}$ and MDA concentrations were not influenced by lower $\mathrm{NaCl}$ concentrations, however, both were remarkably accumulated at increasing $\mathrm{NaCl}$ concentrations (Fig. 6). $\mathrm{H}_{2} \mathrm{O}_{2}$ and MDA contents in leaves of $H$. ammodendron significantly 

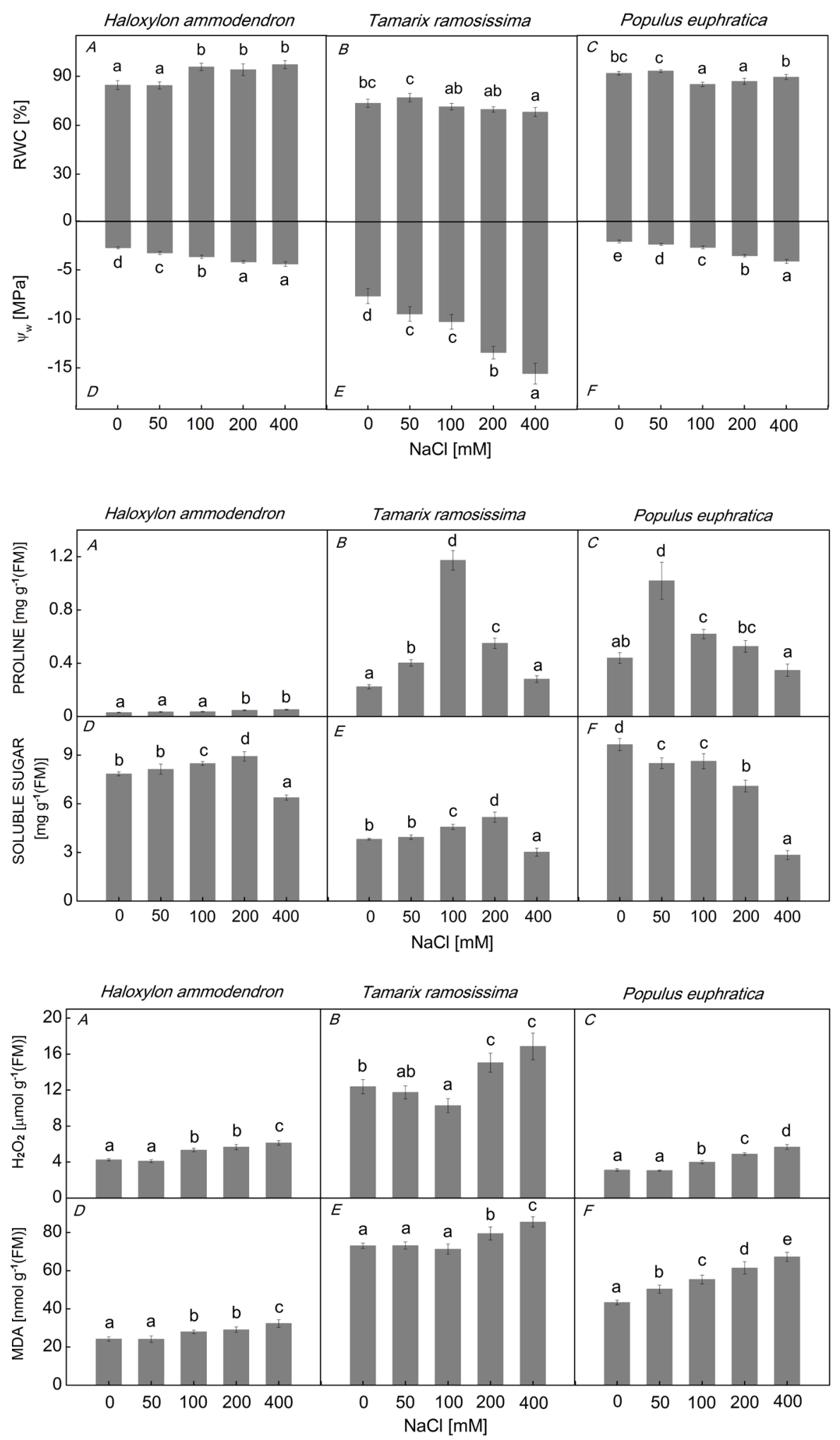

Fig. 4. Effects of $\mathrm{NaCl}$ exposure $(0,50,100,200$, and $400 \mathrm{mM})$ on relative water content (RWC) $(A-C)$ and water potential $\left(\psi_{\mathrm{w}}\right)(D-F)$ in leaves of Haloxylon ammodendron, Tamarix ramosissima, and Populus euphratica. Values are means \pm SD $(n=4)$. Different lowercase letters indicate significant differences at $p<0.05$ according to Fisher's LSD test.

Fig. 5. Effects of $\mathrm{NaCl}$ exposure $(0,50,100,200$, and $400 \mathrm{mM})$ on proline $(A-C)$ and soluble sugar contents $(D-F)$ in leaves of Haloxylon ammodendron, Tamarix ramosissima, and Populus euphratica. Values are means $\pm \operatorname{SD}(n=4)$. Different lowercase letters indicate significant differences at $p<0.05$ according to Fisher's LSD test.

Fig. 6. Effects of $\mathrm{NaCl}$ exposure $(0,50,100,200$, and $400 \mathrm{mM})$ on hydrogen peroxide $\left(\mathrm{H}_{2} \mathrm{O}_{2}\right)(A-C)$ and malondialdehyde (MDA) $(D-F)$ contents in leaves of Haloxylon ammodendron, Tamarix ramosissi$m a$, and Populus euphratica. Values are means \pm SD $(n=4)$. Different lowercase letters indicate significant differences at $p<0.05$ according to Fisher's LSD test. increased under $100 \mathrm{mM} \mathrm{NaCl}$ (Fig. 6A,D), and both $\mathrm{H}_{2} \mathrm{O}_{2}$ and MDA significantly accumulated in leaves of $T$. ramosissima under $200 \mathrm{mM} \mathrm{NaCl}$ (Fig. 6B,E). $\mathrm{H}_{2} \mathrm{O}_{2}$ content in leaves of $P$. euphratica showed a similar tendency as in $H$. ammodendron (Fig. 6C). MDA content was increasing with elevated $\mathrm{NaCl}$ concentrations
$(R=0.999, P<0.001)$ (Fig. $6 F)$.

Antioxidant enzymes: SOD, CAT, POD, and APX activities in leaves of the three species initially increased and then decreased gradually with elevated $\mathrm{NaCl}$ concentrations (Fig. 7). SOD, CAT, POD, and APX activities in 


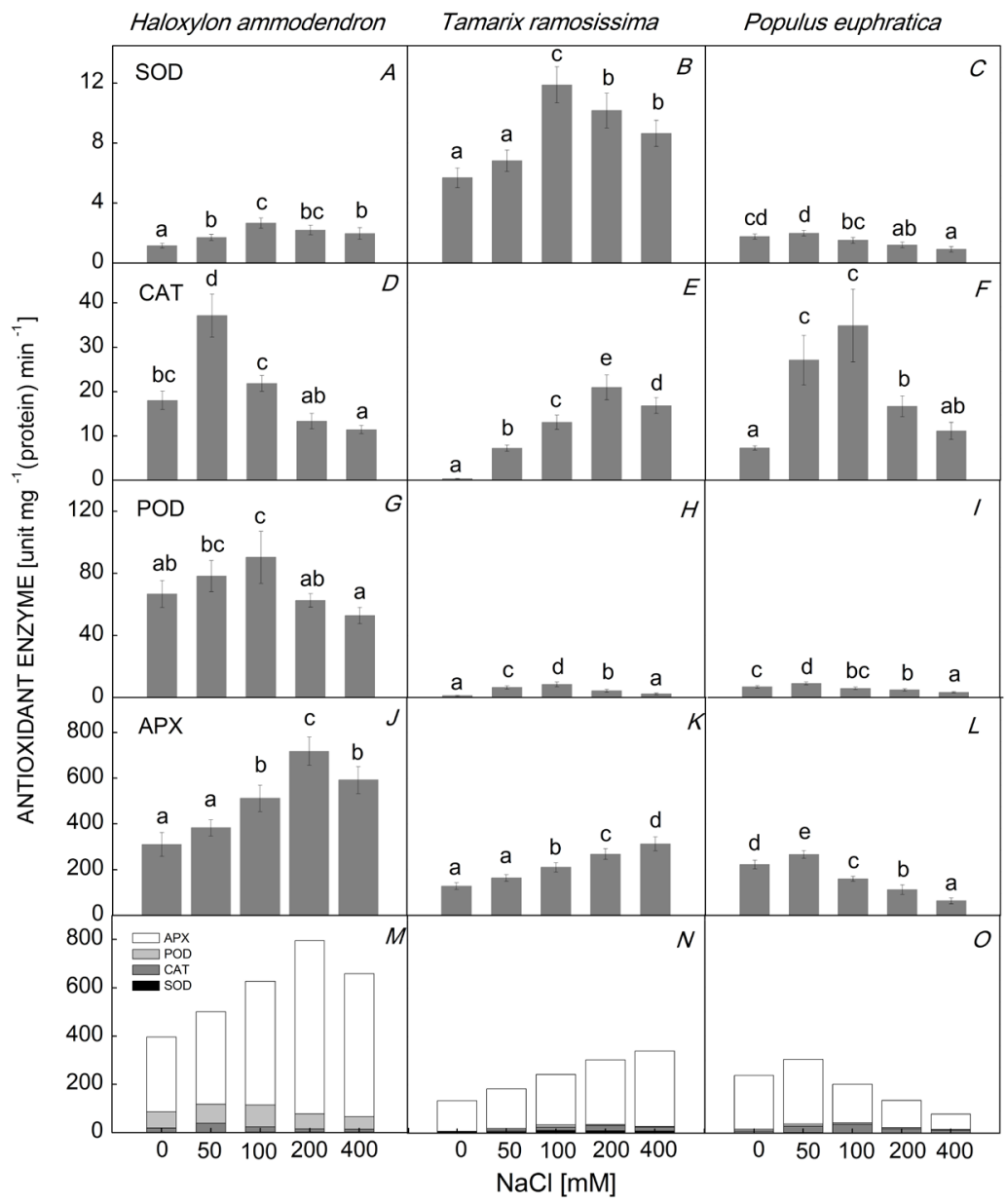

Fig. 7. Effects of $\mathrm{NaCl}$ exposure $(0,50,100$, 200 , and $400 \mathrm{mM}$ ) on superoxide dismutases (SOD) $(A-C)$, catalases (CAT) $(D-F)$, guaiacol peroxidase (POD) $(G-I)$, ascorbate peroxidase (APX) $(J-L)$, and total enzyme activities $(M-O)$ in leaves of Tamarix ramosissima, Populus euphratica, and Haloxylon ammodendron. Values are means \pm SD $(n=4)$. Different lowercase letters indicate significant differences at $p<0.05$ according to Fisher's LSD test.



Fig. 8. Biplot of principal component analysis of the first two principal components of all tested parameters, species and salinity levels. Car - carotenoids; Chl chlorophyll $(a+b)$; Enzyme - total activities of all analyzed antioxidant enzymes; $C_{\mathrm{i}}-$ intercellular $\mathrm{CO}_{2}$ concentration; $E-$ transpiration rate; $g_{\mathrm{s}}$ - stomatal conductance; H. - Haloxylon ammodendron; $\mathrm{H}_{2} \mathrm{O}_{2}$ - hydrogen peroxide; MDA malondialdehyde content; $P$. Populus euphratica; $P_{\mathrm{N}}-$ net photosynthetic rate; RWC relative water content; $T$. - Tamarix ramosissima; WUE - water-use efficiency; $\psi_{\mathrm{w}}-$ water potential; $50-50 \mathrm{mM} \mathrm{NaCl}$ treatment; $100-100 \mathrm{mM} \mathrm{NaCl}$ treatment; $200-200 \mathrm{mM} \mathrm{NaCl}$ treatment; $400-400 \mathrm{mM} \mathrm{NaCl}$ treatment.

leaves of $H$. ammodendron increased with increasing $\mathrm{NaCl}$ concentration and reached their maximum value at 100, 50, 100 , and $200 \mathrm{mM} \mathrm{NaCl}$ concentrations, respectively, and began to decrease with increasing $\mathrm{NaCl}$ treatments. Among these enzymes only CAT decreased significantly lower than the control level under $400 \mathrm{mM} \mathrm{NaCl}$ concentration 
(Fig. $7 A, D, G, J$ ). APX in leaves of $T$. ramosissima increased with increasing $\mathrm{NaCl}$ concentrations (Fig. $7 K$ ); SOD, CAT, and POD initially increased with elevated $\mathrm{NaCl}$ and reached their peak value at 100,200 , and $100 \mathrm{mM} \mathrm{NaCl}$ concentrations, and then began to decrease. POD was reduced to control level under $400 \mathrm{mM} \mathrm{NaCl}$ treatment, however, SOD and CAT were still higher than control level at $400 \mathrm{mM} \mathrm{NaCl}$ treatment (Fig. 7B,E,H). SOD, POD, and APX in leaves of $P$. euphratica peaked at $50 \mathrm{mM} \mathrm{NaCl}$ and then began decreasing under the control level (Fig. $7 C, I, L)$; only CAT peaked at $100 \mathrm{mM} \mathrm{NaCl}$ and was still higher than control level (Fig. $7 F$ ). The total enzyme activities in leaves of $H$. ammodendron initially increased and showed the maximal value at $200 \mathrm{mM} \mathrm{NaCl}$ and then decreased at $400 \mathrm{mM} \mathrm{NaCl}$ being still higher than that of the control (Fig. 7M). The total enzyme activities in leaves of $T$. ramosissima increased with increasing $\mathrm{NaCl}$ concentrations $(R=0.997, P<0.001)($ Fig. $7 N)$, in leaves of $P$. euphratica, it reached the peak value at $50 \mathrm{mM} \mathrm{NaCl}$ concentration, and began to decrease significantly lower than control level with increasing $\mathrm{NaCl}$ concentration (Fig. 7O).

Principle component analysis (PCA): The results of the PCA obtained from data of all physiological and biochemical parameters of the three species subjected to different salinity levels are illustrated in Fig. 8. The first two components accounted for $80.5 \%$ of the total variation, and the first and second PCA accounted for 59.2 and $21.3 \%$ of the total variability, respectively. The leaf toxic ion $\left(\mathrm{Na}^{+}\right.$ and $\mathrm{Cl}^{-}$) content, $\mathrm{Na}^{+} / \mathrm{Ca}^{2+}, \mathrm{Na}^{+} / \mathrm{K}^{+}$, and $\mathrm{Ca}^{2+} / \mathrm{Mg}^{2+}$ ratios together with MDA and $\mathrm{H}_{2} \mathrm{O}_{2}$ concentrations were favored by $H$. ammodendron as well as $P$. euphratica under 200 and $400 \mathrm{mM} \mathrm{NaCl}$ treatment. Interestingly, photosynthetic pigments (Chl, Car, Car/Chl), gas-exchange parameters $\left(P_{\mathrm{N}}, E, g_{\mathrm{s}}\right)$ were grouped with soluble sugar, antioxidant enzymes, RWC, $\psi_{\mathrm{w}}$, and $\mathrm{Mg}^{2+}$, and the angle among the vectors of these parameters was acute. All of the three species were identified by these parameters when treated with lower $\mathrm{NaCl}$ concentrations $(50 \mathrm{mM})$, except for T. ramosissima under $400 \mathrm{mM} \mathrm{NaCl}$.

\section{Discussion}

Exposure of plants to stress conditions such as salinity not only reduces the total quantity of photosynthetic energy obtained by plants but also rearranges energy from growth to endurance processes such as ion homeostasis, decreasing oxidative damages, and osmotic regulation (Munns and Gilliham 2015).

Effects of salinity on ion concentrations: $\mathrm{NaCl}$ induced ion toxicity associated with the overaccumulation of $\mathrm{Na}^{+}$ and $\mathrm{Cl}^{-}$, and there were significant differences between species in the capacity for uptaking and utilizing of $\mathrm{Na}^{+}$ and $\mathrm{Cl}^{-}$; consequently, these three species displayed different salt-resistance mechanisms. H. ammodendron is a leaf succulent plant that can deposit a high amount of $\mathrm{Na}^{+}$and $\mathrm{Cl}^{-}$in leaves. Succulence is considered to contribute to salt adjustment by enlarging the vacuolar volume convenient to ion accumulation (Greenway and Munns 1980, Ungar 1991). Halogeton glomeratus, a succulent halophyte, took up a large quantity of $\mathrm{Na}^{+}$in water-storage tissue in leaves, sustained the succulence of leaves, and also the water content of tissues in response to salt stresses (Wang et al. 2015). Tamarix species acquire ions by the root system and then transport the ions to salt glands in leaves using an apoplastic xylem pathway (Campbell et al. 1974). In this study, $\mathrm{Na}^{+}$in leaves of $T$. ramosissima accumulated significantly only under higher $\mathrm{NaCl}$ concentrations $(\geq 200 \mathrm{mM} \mathrm{NaCl})$; the similar results had been reported in recretohalophyte Atriplex centralasiatica (Li et al. 2006). Tamarix sp. uses excretion processes to remove salt ions and the glandular structures are not always specific to $\mathrm{Na}^{+}$and $\mathrm{Cl}^{-}$, and other toxic ions such as $\mathrm{Cd}^{2+}, \mathrm{Li}^{+}$, and $\mathrm{Pb}^{2+}$ are also excreted by the salt glands on the surface of the leaves (Hagemeyer and Waisel 1988, Kadukova et al. 2008, Manousaki and Kalogerakis 2011). The capacity of $P$. euphratica to exclude $\mathrm{Na}^{+}$and $\mathrm{Cl}^{-}$is associated with restricted root-to-shoot salt transport caused by the blocking of root apoplastic salt transport and sequestration of $\mathrm{Cl}^{-}$in root cortical vacuoles (Chen et al. 2003, Wang et al. 2008). However, excessive accumulation of $\mathrm{Na}^{+}$in leaves of $P$. euphratica treated with higher $\mathrm{NaCl}$ concentrations indicates that the effective system for root exclusion, accumulation in shoots, and/or weakened $\mathrm{Na}^{+}$ xylem transport were not working to restrain this toxic ion to reach the leaves (Munns et al. 2005).

$\mathrm{K}^{+}, \mathrm{Ca}^{2+}$, and $\mathrm{Mg}^{2+}$ take a great part in plant growth and development but also in the maintenance of cell turgor and osmotic regulation (Marschner 1995, Veatch-Blohm et al. 2012, Acosta-Motos et al. 2014). However, $\mathrm{K}^{+}$in roots of $P$. euphratica decreased significantly with an elevated level of salinity, as reported by Chen et al. (2001), owing to a competitive process between $\mathrm{K}^{+}$and $\mathrm{Na}^{+}$in the root medium. Since salinity increased $\mathrm{Na}^{+}$concentration in plants, it competed with $\mathrm{K}^{+}, \mathrm{Mg}^{2+}$, and $\mathrm{Ca}^{2+}$ which increased $\mathrm{Na}^{+} / \mathrm{K}^{+}, \mathrm{Na}^{+} / \mathrm{Mg}^{2+}$, and $\mathrm{Na}^{+} / \mathrm{Ca}^{2+}$ ratios, inducing a disorder of $\mathrm{K}^{+}, \mathrm{Ca}^{2+}$, and $\mathrm{Mg}^{2+}$-dependent metabolic processes in plants, causing cellular damage, decreases in net photosynthesis, and inhibition of growth (Carter et al. 2006).

Photosynthetic pigment and gas-exchange characteristics: Salinity severely impacts photosynthesis by the reduction in Chl and Car contents (Lu et al. 2017, Li et al. 2020), as was also seen in species in the present research at higher $\mathrm{NaCl}$ concentrations. In this study, P. euphratica showed a higher reduction in $\mathrm{Chl}$, Car, and $\mathrm{Car} / \mathrm{Chl}$, and the significant reduction began at lower $\mathrm{NaCl}$ concentration than that of $H$. ammodendron and T. ramosissima. A decrease of $\mathrm{Chl}$ has often been linked to salinity stress (Borrelli et al. 2018, Hinojosa-Vidal et al. 2018). Reduction in Chl content might be attributed to direct salt stress effects on Chl degradation due to weakening bonds of the pigment-protein-lipid complex (Levitt 1980), Mg accumulation, and resulting in restrains of Chl synthesis; or salinity could promote the activity 
of the Chl-degrading enzyme chlorophyllase (Reddy and Vora 1986). The interconversion of Chl $a$ and $b$ effectively works on the establishment of desired $\mathrm{Chl} a / b$ ratio during the regulation of leaves to stress conditions (Ito et al. 1993). In our research, with the elevated $\mathrm{NaCl}$ concentration $(\geq 100 \mathrm{mM} \mathrm{NaCl})$, the ratio of $\mathrm{Chl} a / b$ enhanced markedly in leaves of $P$. euphratica, suggesting a reduction of the light-harvesting complex of PSII (Pandey et al. 2009), or reduction in the LHC components because $\mathrm{Chl} b$ is mainly located in the complexes (Durnford et al. 2003). Cars are related to the photosynthetic complexes in thylakoid membranes. They harvest photons, keep the structure and function of the photosynthetic complexes, eliminate excess energy, and quench Chl triplet states (DemmigAdams et al. 1996, Niyogi et al. 1999). In this study, Car concentration and $\mathrm{Car} / \mathrm{Chl}$ ratio decreased under higher $\mathrm{NaCl}$ concentrations, especially in leaves of $P$. euphratica, suggesting that the energy dissipation mechanism failed to reduce the excess energy in PSI and PSII (Lu et al. 2003, Pandey et al. 2005).

The reduction in the Chl content caused the decrease of $P_{\mathrm{N}}$, and changed $g_{\mathrm{s}}$, inducing stomatal closure (Verslues et al. 2006). $P_{\mathrm{N}}$ of a plant normally decreases with elevated salinity stress (Garcia et al. 2017, Ahanger et al. 2020). In this study, the decrease of $P_{\mathrm{N}}$ reported in $P$. euphratica was more significant compared to $H$. ammodendron and T. ramosissima, and the variations in $P_{\mathrm{N}}$ were in accordance with Chl content changes. $P_{\mathrm{N}}$ exhibited a highly remarkable correlation with $g_{\mathrm{s}}$, which suggested that stomatal closure drove, at least in part, $P_{\mathrm{N}}$ reduction under salt stress. It has been proven that long-term exposure to salt reduced $P_{\mathrm{N}}$, which might be due to decreased $g_{\mathrm{s}}$ (Ouerghi et al. 2000). Leaf stomata closure attributed to toxic $\mathrm{Na}^{+}$and $\mathrm{Cl}^{-}$ions reduces $g_{\mathrm{s}}$, which further reduces $P_{\mathrm{N}}$ and growth (Shahbaz and Zia 2011). The $P_{\mathrm{N}}$ and $g_{\mathrm{s}}$ were highly correlated with $C_{\mathrm{i}}$ values. A reduction in $C_{\mathrm{i}}$ should be accompanied by the reduction in $P_{\mathrm{N}}$ if stomatal limitations to $\mathrm{CO}_{2}$ diffusion are a major limitation (Farquhar and Sharkey 1982). The subsequent increase in $C_{\mathrm{i}}$ could suggest nonstomatal limitations (Moya et al. 2002, Duan et al. 2018). Stomatal limitations are usually prominent in moderate salt environments, however, nonstomatal limitations are significant in high salt environments (Everard et al. 1994). In this study, the decreases in $P_{\mathrm{N}}$ and $g_{\mathrm{s}}$ in leaves of $H$. ammodendron and $P$. euphratica were accompanied by the increase in $C_{\mathrm{i}}$ with increasing $\mathrm{NaCl}$ concentrations, which indicated nonstomatal limitations. However, the decreases in $P_{\mathrm{N}}$ and $g_{\mathrm{s}}$ accompanied by higher $C_{\mathrm{i}}$ in leaves of $T$. ramosissima were present only under $400 \mathrm{mM} \mathrm{NaCl}$, indicating that a nonstomatal factor was responsible for the reduction of photosynthesis at high salinity. Similar results were found in previous studies of Malus halliana, M. robusta (Zhu et al. 2019), and Suaeda glauca (Duan et al. 2018) under salinity stress conditions. It can be concluded therefore that the decrease in the $P_{\mathrm{N}}$ reported herein was due to biochemical limitations, such as a decline in photosynthetic pigments and salinity-induced oxidative stress (Huang et al. 2014, Panda et al. 2019). Furthermore, stomatal closure reduces the loss of water through transpiration, resulting in a decrease of $E$. It has been reported that the reduction in $g_{\mathrm{s}}$ under mild stress may be a protective mechanism against stress by allowing the plant to conserve water, consequently improving plant WUE (Chaves et al. 2009).

RWC, $\psi_{w}$, and compatible solute content: Salinity first weakens the plant's capacity of absorbing water, consequently, results in physiological water deficit. Water relations and the capacity of regulating the osmotic concentration take a great part in the development and overall growth of plants (Munns 2002). It has been reported that plants accumulate osmolytes or inorganic ions in saline environments to reduce their cellular water potential (Munns 2002, Shafeiee and Ehsanzadeh 2019). Sodium and chloride are regarded as energetically efficient osmolytes for osmotic regulation and are usually compartmentalized into the vacuole to minimize cytotoxicity (Blumwald et al. 2000). Moreover, soluble sugars and proline are principal compatible solutes involved in osmotic adjustment (Singh et al. 2015, Ahanger et al. 2020). In this study, the reduction of leaf water potential $\left(\psi_{\mathrm{w}}\right)$ in salt-treated plants indicates an osmotic effect and as a consequence difficulty for water uptake. High salinity exposure caused a significant increment in RWC in leaves of $H$. ammodendron. The capacity of $H$. ammodendron to hold relatively high RWC in leaves exposed to high salt treatments seems to play a protective role from the deleterious influences of excessive salt. In halophytes, enhanced leaf succulency could be a representative adaptive response and is accomplished by enlarging the size of mesophyll cells and the relative size of vacuoles (Shabala and Mackay 2011, Parida et al. 2016). Proline and soluble sugar in leaves of $H$. ammodendron increased slowly and soluble sugar even decreased significantly exposed to $400 \mathrm{mN} \mathrm{NaCl}$ compared with control. On the contrary, an enhancement of external $\mathrm{NaCl}$ from 50 to $400 \mathrm{mM}$ led to a remarkable accumulation in internal $\mathrm{Na}^{+}$and $\mathrm{Cl}^{-}$, indicating that the $\mathrm{Na}^{+}$and $\mathrm{Cl}^{-}$were the main contributor to osmotic regulation responding to low external water potential in $H$. ammodendron. It has been demonstrated that the accumulation of $\mathrm{Na}^{+}$can mitigate the detrimental effects of osmotic stress induced by salinity stress in other succulent plants (Ma et al. 2012, 2016); $\mathrm{Cl}^{-}$ is beneficial for the growth of the xerophyte Pugionium cornutum by enhancing osmotic adjustment capacity under salt stresses (Cui et al. 2020). However, RWC in leaves of T. ramosissima was reduced progressively with increasing $\mathrm{NaCl}$ concentration. In general, plants can take water loss as a quick and economical way to osmotic regulation in response to osmotic stress (Lissner et al. 1999). Remarkable accumulations of proline and soluble sugars in leaves of $T$. ramosissima, except for $400 \mathrm{mM} \mathrm{NaCl}$ treatment, were detected under salt stress in comparison with control, suggested the accumulation of sucrose and proline could be an adaptive mechanism to restrain water loss. RWC in leaves of $P$. euphratica decreased initially, and the proline content increased compared to control $(\leq 200 \mathrm{mM} \mathrm{NaCl})$, meanwhile, $\mathrm{Na}^{+}$and $\mathrm{Cl}^{-}$were only significantly accumulated at higher $\mathrm{NaCl}$ treatment 
compared with control ( $\geq 200 \mathrm{mM} \mathrm{NaCl}$ ). In $P$. euphratica, proline might play an important role in osmotic adjustment under lower salinity stress, however, $\mathrm{Na}^{+}$and $\mathrm{Cl}^{-}$might be the main contributor to alleviate the osmotic pressure in response to higher salinity stress.

MDA, $\mathrm{H}_{2} \mathrm{O}_{2}$ content, and enzyme activities: Oxidative stress is a consequence that has been considered as one of the main factors inducing cellular damage in plants subjected to diverse abiotic stresses, including salt stress (Singh et al. 2015, Chen et al.2020). Salinity could induce oxidative stress by a generation of ROS in higher plants (Singh et al. 2015, Jiang et al. 2020). Protonation of $\mathrm{O}_{2}{ }^{-}$generates the hydroperoxyl radical ( $\mathrm{HO}$ and $\mathrm{H}_{2} \mathrm{O}_{2}$ ), which can change fatty acids into toxic lipid peroxides and damage biological membranes (Weckx and Clijsters 1996). MDA is a substance produced by lipid peroxidation while plants are subjected to oxidative stress and could be considered as a marker of the extent of oxidative stress (Li et al. 2017, El-Esawi et al. 2018). In the present study, high concentrations of $\mathrm{NaCl}$ remarkably enhanced the generation of $\mathrm{H}_{2} \mathrm{O}_{2}$, thereby, resulting in lipid peroxidation as evidence by the accumulation of MDA. However, oxidative damage was lesser in $H$. ammodendron and T. ramosissima than that in P. euphratica, as shown by the lower MDA concentration in leaves.

Salt-evoked oxidative damage can be relieved by the active response of the antioxidative system; antioxidative ability is generally regarded as the standard for selecting salt-tolerant species. Plants' pivotal ROS-scavenging mechanisms contain SOD, CAT, APX, and POD, and the balance between them is crucial (Mittler 2002, Asrar et al. 2020). SOD is the key antioxidant enzyme working as $\mathrm{O}_{2}^{-}$ scavenger in living organisms through promptly changing $\mathrm{O}_{2}{ }^{--}$into $\mathrm{O}_{2}$ and $\mathrm{H}_{2} \mathrm{O}_{2}$, a first-line protector from oxidative stress induced by ROS. In the present study, induction of SOD was recorded in leaves of $H$. ammodendron and T. ramosissima but not in $P$. euphratica leaves exposed to higher salt concentrations. However, the substance generated by SOD activity is $\mathrm{H}_{2} \mathrm{O}_{2}$, and that remains toxic and should be removed by change into $\mathrm{H}_{2} \mathrm{O}$ in the next process. In plants, CAT, APX, and POD are regarded as the most important in the degradation of $\mathrm{H}_{2} \mathrm{O}_{2}$ (Blokhina et al. 2003, Jiang et al. 2020). In this study, an enhancement in SOD activity in leaves of $T$. ramosissima subjected to all $\mathrm{NaCl}$ exposure concentrations occurred together with an enhancement in CAT, POD, and APX, which guaranteed the efficient removing of $\mathrm{H}_{2} \mathrm{O}_{2}$ by a reduced production of $\mathrm{H}_{2} \mathrm{O}_{2}$ at lower $\mathrm{NaCl}$ concentration $(\leq 100 \mathrm{mM} \mathrm{NaCl})$ and slower accumulation rate at higher $\mathrm{NaCl}$ concentration ( $\geq 200 \mathrm{mM} \mathrm{NaCl}$ ). In $H$. ammodendron, $\mathrm{H}_{2} \mathrm{O}_{2}$ was eliminated by POD and CAT at lower and by APX at higher salinity stress. However, in $P$. euphratica, the significant accumulation of $\mathrm{H}_{2} \mathrm{O}_{2}$ measured at high $\mathrm{NaCl}$ treatments ( $\geq 100 \mathrm{mM}$ ) may be owed to a gradual reduction in SOD, CAT, POD, and APX activities. It has been reported that activities of antioxidative enzymes were significantly higher in the tolerant species in comparison to sensitive ones exposed to salinity stress (Kaya et al. 2015, Ibrahim et al. 2019). The ROS-scavenging system in T. ramosissima and $H$. ammodendron was more efficient in comparison to P. euphratica, as CAT, POD, and APX together with SOD activity in leaves of T. ramosissima and $H$. ammodendron reacted more efficiently in $\mathrm{O}_{2}{ }^{-}$and $\mathrm{H}_{2} \mathrm{O}_{2}$ scavenging. Our results suggested that $T$. ramosissima and $H$. ammodendron may better defend against oxidative stress and can promptly modulate the antioxidant system.

Evaluation of salt-tolerance parameters by principal component analysis: Principal component analyses (PCAs) could present an overall explanation of the interrelationships between tested indexes. It screens which parameters could be considered as interchangeable, individual, or supplementary criteria for estimating salt tolerance when exposed to salt stress (El-Hendawy et al. 2017). The interrelationships between parameters can be explained by the angles between the parameter vectors. An acute angle suggests strong correlations, and the reverse is also true for the obtuse angle. A straight angle indicates a negative correlation between parameters, while a right angle illustrates no correlation between parameters (El-Hendawy et al. 2017). According to this theory, the leaf oxidative stress parameters $\left(\mathrm{H}_{2} \mathrm{O}_{2}\right.$ and MDA) together with toxic ion concentrations and ion ratios $\left(\mathrm{Na}^{+}\right.$, $\mathrm{Cl}^{-}, \mathrm{Na}^{+} / \mathrm{Ca}^{2+}, \mathrm{Na}^{+} / \mathrm{K}^{+}$, and $\mathrm{Ca}^{2+} / \mathrm{Mg}^{2+}$ ) were grouped. Moreover, the leaf photosynthetic parameters (photosynthetic pigments and gas-exchange parameters) were grouped with soluble sugar, antioxidant enzymes, and $\psi_{\mathrm{w}}$. Therefore, these parameters, in these two groups respectively, represented a strong correlation between them and recommended to be taken as complementary screening criteria for salt tolerance evaluation. The straight angle between toxic ion, $\mathrm{H}_{2} \mathrm{O}_{2}, \mathrm{MDA}$, and photosynthetic parameters, soluble sugar, enzymes, and $\psi_{\mathrm{w}}$ suggests that salinity can cause ion toxicity, osmotic and oxidative stress through the excessive accumulation of toxic ions $\mathrm{CNa}^{+}$and $\left.\mathrm{Cl}^{-}\right), \mathrm{H}_{2} \mathrm{O}_{2}$, and MDA, however, a plant can alleviate the stress by the accumulation of soluble sugars and promotion of antioxidative enzyme activities. Therefore, the toxic ion contents $\left(\mathrm{Na}^{+}\right.$and $\left.\mathrm{Cl}^{-}\right)$, ion ratios $\left(\mathrm{Na}^{+} / \mathrm{Ca}^{2+}, \mathrm{Na}^{+} / \mathrm{K}^{+}\right.$, and $\left.\mathrm{Ca}^{2+} / \mathrm{Mg}^{2+}\right), \mathrm{H}_{2} \mathrm{O}_{2}, \mathrm{MDA}$, photosynthesis parameters, soluble sugars, enzymes, and $\psi_{\mathrm{w}}$ could be considered as interchangeable or individual screening criteria for salt tolerance evaluation.

Conclusion: All three woody plant species are well adapted to the mild salinity exposure $(\leq 50 \mathrm{mM} \mathrm{NaCl})$, indicating that those plant species possess moderate salt tolerance capacity and can grow well under the mild saline conditions of the groundwater in the southern rim of the Taklamakan Desert. Nevertheless, the plants showed different salttolerance mechanisms. While $H$. ammodendron acquired a large quantity of mineral salts and deposited salts in leaf, $\mathrm{Na}^{+}$in leaves of $T$. ramosissima accumulated significantly only under higher $\mathrm{NaCl}$ treatments $(\geq 200 \mathrm{mM} \mathrm{NaCl})$, P. euphratica restricted excessive $\mathrm{Na}^{+}$and $\mathrm{Cl}^{-}$accumulation in leaves by root exclusion and transport pathway from roots to shoots. Furthermore, there were substantial differences in the response of antioxidant enzymes to salinity stresses and salinity evoked oxidative damage in 
the three species. The higher $\mathrm{Na}^{+}$and $\mathrm{Cl}^{-}$concentrations, lower oxidative damage, and more efficient antioxidant enzyme activities suggested that $H$. ammodendron and T. ramosissima depended on the antioxidant protective mechanisms to defend against oxidative stress. Our results indicate the better tolerance of $H$. ammodendron and T. ramosissima to salinity stress compared to $P$. euphratica.

\section{References}

Acosta-Motos J.R., Álvarez S., Barba-Espín G. et al.: Salts and nutrients present in regenerated waters induce changes in water relations, antioxidative metabolism, ion accumulation and restricted ion uptake in Myrtus communis L. plants. Plant Physiol. Bioch. 85: 41-50, 2014.

Aebi H.: Catalase in vitro. - Method. Enzymol. 105: 121-126, 1984.

Ahanger M.A., Mir R.A., Alyemeni M.N., Ahmad P.: Combined effects of brassinosteroid and kinetin mitigates salinity stress in tomato through the modulation of antioxidant and osmolyte metabolism. - Plant Physiol. Bioch. 147: 31-42, 2020.

Allakhverdiev S.I., Kreslavski V.D., Klimov V.V. et al.: Heat stress: an overview of molecular responses in photosynthesis.Photosynth. Res. 98: 541-550, 2008.

Arndt S.K., Arampatsis C., Foetzki A. et al.: Contrasting patterns of leaf solute accumulation and salt adaptation in four phreatophytic desert plants in a hyperarid desert with saline groundwater. - J. Arid Environ. 59: 259-270, 2004.

Asrar H., Hussain T., Qasim M. et al.: Salt induced modulations in antioxidative defense system of Desmostachya bipinnata.Plant Physiol. Bioch. 147: 113-124, 2020.

Bates L.S., Waldren R.P., Teare I.D.: Rapid determination of free proline for water stress studies. - Plant Soil 39: 205-207, 1973.

Beauchamp C., Fridovich I.: Superoxide dismutase: improved assays and an assay applicable to acrylamide gels. - Anal. Biochem. 44: 276-287, 1971.

Blokhina O., Virolainen E., Fagerstedt K.V.: Antioxidants, oxidative damage and oxygen deprivation stress: a review. Ann. Bot.-London 91: 179-194, 2003.

Blumwald E., Aharon G.S., Apse M.P.: Sodium transport in plant cells. - BBA-Biomembranes 1465: 140-151, 2000.

Borrelli G.M., Fragasso M., Nigro F. et al.: Analysis of metabolic and mineral changes in responses to salt stress in durum wheat (Triticum turgidum ssp. durum) genotypes, which differ in salinity tolerance. - Plant Physiol. Bioch. 133: 57-70, 2018.

Bradford M.M.: A rapid and sensitive method for the quantification of microgram quantities of protein utilizing the principle of protein-dye binding. - Anal. Biochem. 72: 248254, 1976

Campbell N., Thomson W.W., Platt K.: The apoplastic pathway of transport to salt glands. - J. Exp. Bot. 25: 61-69, 1974.

Carter J.L., Colmer T.D., Veneklaas E.J.: Variable tolerance of wetland tree species to combined salinity and waterlogging is related to regulation of ion uptake and production of organic solutes. - New Phytol. 169: 123-134, 2006.

Chance B., Maehly A.C.: Assay of catalases and peroxidases. - In: Colowick S.P., Kaplan N.O. (ed.): Methods in Enzymology. Pp. 764-775. Academic Press, New York 1955.

Chaves M.M., Flexas J., Pinheiro C.: Photosynthesis under drought and salt stress: regulation mechanisms from whole plant to cell. - Ann. Bot.-London 103: 551-560, 2009.

Chen J., Zhang H., Zhang X., Tang M.: Arbuscular mycorrhizal symbiosis mitigates oxidative injury in black locust under salt stress through modulating antioxidant defense of the plant. Environ. Exp. Bot. 175: 104034, 2020.

Chen S., Li J., Wang S. et al:: Salt, nutrient uptake and transport, and ABA of Populus euphratica: a hybrid in response to increasing soil NaCl. - Trees 15: 186-194, 2001.

Chen S., Li J., Wang S. et al:: Effects of $\mathrm{NaCl}$ on shoot growth, transpiration, ion compartmentation and transport in regenerated plants of Populus euphratica and Populus tomentosa. - Can. J. For. Res. 33: 967-975, 2003.

Cui Y.N., Li X.T., Yuan J.Z. et al.: Chloride is beneficial for growth of the xerophyte Pugionium cornutum by enhancing osmotic adjustment capacity under salt and drought stresses. J. Exp. Bot. 71: 4215-4231, 2020.

Cui Y.Q., Ma J.Y., Sun W.: Application of stable isotope techniques to the study of soil salinization. - J. Arid Land 3 : 285-291, 2011. doi: 10.3724/SP.J.1227.2011.00285.

Demmig-Adams B., Gilmore A.M., Adams III W.W.: In vivo functions of carotenoids in higher plants. - FASEB J. 10: $403-$ 412, 1996.

Duan H., Ma Y., Liu R. et al.: Effect of combined waterlogging and salinity stresses on euhalophyte Suaeda glauca. - Plant Physiol. Bioch. 127: 231-237, 2018.

Durnford D.G., Price J.A., McKim S.M., Sarchfield M.L.: Lightharvesting complex gene expression is controlled by both transcriptional and posttranscriptional mechanisms during photoacclimation in Chlamydomonas reinhardtii. - Physiol. Plantarum 118: 193-205, 2003.

El-Esawi M.A., Alaraidh I.A., Alsahli A.A. et al.: Bacillus firmus (SW5) augments salt tolerance in soybean (Glycine max L.) by modulating root system architecture, antioxidant defense systems and stress-responsive genes expression. - Plant Physiol. Bioch. 132: 375-384, 2018.

El-Hendawy S.E., Hassan W.M., Al-Suhaibani N.A. et al.: Comparative performance of multivariable agro-physiological parameters for detecting salt tolerance of wheat cultivars under simulated saline field growing conditions. - Front. Plant Sci. 8: 435, 2017.

Everard J.D., Gucci R., Kann S.C. et al.: Gas exchange and carbon partitioning in the leaves of celery (Apium graveolens L.) at various levels of root zone salinity. - Plant Physiol. 106: 281-292, 1994.

Fan L., Wang G.N., Hu W. et al.: Transcriptomic view of survival during early seedling growth of the extremeophyte Haloxylon ammodendron. - Plant Physiol. Bioch. 132: 475-489, 2018.

FAO, ITPS: Status of the World's Soil Resources (SWSR). Main Report. Pp. 650. Food and Agriculture Organization of the United Nations and Intergovernmental Technical Panel on Soils, Rome 2015.

Farquhar G.D., Sharkey T.D.: Stomatal conductance and photosynthesis. - Ann. Rev. Plant Physio. 33: 317-345, 1982.

Garcia J.D., Dalmolin Â.C., França M.G.C., Mangabeira P.A.O.: Different salt concentrations induce alterations both in photosynthetic parameters and salt gland activity in leaves of the mangrove Avicennia schaueriana. - Ecotox. Environ. Safe. 141: 70-74, 2017.

Gechev T., Petrov V.: Reactive oxygen species and abiotic stress in plants. - Int. J. Mol. Sci. 21: 7433, 2020.

Gibert E., Gentelle P., Liang K.Y.: Chemical and isotopic evolution of surficial waters in the Taklamakan desert (Southern Xinjiang, China). - In: Isotopes in Water Resources Management: Proceedings of a Symposium on Isotopes in Water Resources Management, 20-24 March 1995. Pp. 211212. IAEA, Vienna 1996

Greenway H., Munns R.: Mechanisms of salt tolerance in nonhalophytes. - Ann. Rev. Plant Physio. 31: 149-190, 1980.

Hagemeyer J., Waisel Y.: Excretion of ions $\left(\mathrm{Cd}^{2+}, \mathrm{Li}^{+}, \mathrm{Na}^{+}\right.$and 
$\mathrm{Cl}^{-}$) by Tamarix aphylla. - Physiol. Plantarum 73: 541-546, 1988.

Hinojosa-Vidal E., Marco F., Martínez-Alberola F. et al.: Characterization of the responses to saline stress in the symbiotic green microalga Trebouxia sp. TR9. - Planta 248: 1473-1486, 2018

Huang C.J., Wei G., Jie Y.C. et al.: Effects of concentrations of sodium chloride on photosynthesis, antioxidative enzymes, growth and fiber yield of hybrid ramie. - Plant Physiol. Bioch. 76: 86-93, 2014.

Ibrahim W., Qiu C.W., Zhang C. et al.: Comparative physiological analysis in the tolerance to salinity and drought individual and combination in two cotton genotypes with contrasting salt tolerance. - Physiol. Plantarum 165: 155-168, 2019.

Ito H., Tanaka Y., Tsuji H., Tanaka A.: Conversion of chlorophyll $b$ to chlorophyll $a$ by isolated cucumber etioplasts. Arch. Biochem. Biophys. 306: 148-151, 1993.

Jiang D.X., Chu X., Li M. et al.: Exogenous spermidine enhances salt-stressed rice photosynthetic performance by stabilizing structure and function of chloroplast and thylakoid membranes. - Photosynthetica 58: 61-71, 2020.

Kadukova J., Manousaki E., Kalogerakis N.: Pb and $\mathrm{Cd}$ accumulation and phyto-excretion by salt cedar (Tamarix smyrnensis Bunge). - Int. J. Phytoremediat. 10: 31-46, 2008.

Kaya C., Ashraf M., Sonmez O. et al.: Exogenous application of thiamin promotes growth and antioxidative defense system at initial phases of development in salt-stressed plants of two maize cultivars differing in salinity tolerance. - Acta Physiol. Plant. 37: 1741, 2015.

Kosugi H., Kikugawa K.: Thiobarbituric acid reaction of aldehydes and oxidized lipids in glacial acetic acid. - Lipids 20: 915-920, 1985.

Levitt J.: Responses of Plants to Environmental Stresses: Water, Radiation, Salt and Other Stresses. Pp. 607. Academic Press, New York 1980

Li N.N., Wang X., Ma B.J. et al.: Expression of a $\mathrm{Na}^{+} / \mathrm{H}^{+}$ antiporter RtNHX1 from a recretohalophyte Reaumuria trigyna improved salt tolerance of transgenic Arabidopsis thaliana. - J. Plant Physiol. 218: 109-120, 2017.

Li P., Zhu Y., Song X., Song F.: Negative effects of long-term moderate salinity and short-term drought stress on the photosynthetic performance of Hybrid Pennisetum. - Plant Physiol. Bioch. 155: 93-104, 2020.

Li W.Q., Liu X.J., Zhao K.F., Liu H.L.: [Growth, development and ions distribution of three halophytes under salt stress.] Chin. J. Eco.-Agr. 14: 49-52, 2006. [In Chinese]

Lichtenthaler H.K.: Chlorophylls and carotenoids: Pigments of photosynthetic biomembranes. - Method. Enzymol. 148: 350382, 1987.

Lissner J., Schierup H.H., Comín F.A., Astorga V.: Effect of climate on the salt tolerance of two Phragmites australis populations. I. Growth, inorganic solutes, nitrogen relations and osmoregulation. - Aquat. Bot. 64: 317-333, 1999.

López-Serrano L., Canet-Sanchis G., Selak G.V. et al.: Physiological characterization of a pepper hybrid rootstock designed to cope with salinity stress. - Plant Physiol. Bioch. 148: 207-219, 2020.

Lu C., Jiang G., Wang B., Kuang T.: Photosystem II photochemistry and photosynthetic pigment composition in salt-adapted halophyte Artimisia anethifolia grown under outdoor conditions. - J. Plant Physiol. 160: 403-408, 2003.

Lu Y., Lei J.Q., Zeng F.J. et al.: Effect of $\mathrm{NaCl}$-induced changes in growth, photosynthetic parameters, water status and enzymatic antioxidant system of Calligonum caput-medusae Schrenk seedlings. - Photosynthetica 55: 96-106, 2017.

Lu Y., Li X.R., He M.Z. et al.: Seedling growth and antioxidative enzymes activities in leaves under metal stress differ between two desert plants: a perennial (Peganum harmala) and an annual (Halogeton glomeratus) grass. - Acta Physiol. Plant. 32: 583-590, 2010.

Ma Q., Bao A.K., Chai W.W. et al.: Transcriptomic analysis of succulent xerophyte Zygophyllum xanthoxylum in response to salt treatment and osmotic stress. - Plant Soil 402: 343-361, 2016.

Ma Q., Yue L.J., Zhang J.L. et al.: Sodium chloride improves photosynthesis and water status in the succulent xerophyte Zygophyllum xanthoxylum. - Tree Physiol. 32: 4-13, 2012.

Manousaki E., Kalogerakis N.: Halophytes - An emerging trend in phytoremediation. - Int. J. Phytoremediat. 13: 959-969, 2011.

Marschner H.: Mineral Nutrition of Higher Plants. $2^{\text {nd }}$ Edition. Pp. 889. Academic Press, London 1995.

Min X.J., Zang Y.X., Sun W., Ma J.Y.: Contrasting water sources and water-use efficiency in coexisting desert plants in two saline-sodic soils in northwest China. - Plant Biol. 21: 1150$1158,2019$.

Mittler R.: Oxidative stress, antioxidants and stress tolerance. Trends Plant Sci. 7: 405-410, 2002.

Moya J.L., Tadeo F.R., Gómez-Cadenas A. et al.: Transmissible salt tolerance traits identified through reciprocal grafts between sensitive Carrizo and tolerant Cleopatra citrus genotypes. - J. Plant Physiol. 159: 991-998, 2002.

Munns R.: Comparative physiology of salt and water stress. Plant Cell Environ. 25: 239-250, 2002.

Munns R.: Genes and salt tolerance: bringing them together. New Phytol. 167: 645-663, 2005.

Munns R., Gilliham M.: Salinity tolerance of crops - what is the cost? - New Phytol. 208: 668-673, 2015.

Munns R., James R.A., Läuchli A.: Approaches to increasing the salt tolerance of wheat and other cereals. - J. Exp. Bot. 57: 1025-1043, 2005.

Nakano Y., Asada K.: Hydrogen peroxide is scavenged by ascorbate-specific peroxidase in spinach chloroplasts. - Plant Cell Physiol. 22: 867-880, 1981.

Niyogi K.K.: Photoprotection revisited: genetic and molecular approaches. - Annu. Rev. Plant Phys. 50: 333-359, 1999.

Ouerghi Z., Cornic G., Roudani M. et al.: Effect of $\mathrm{NaCl}$ on photosynthesis of two wheat species (Triticum durum and T. aestivum) differing in their sensitivity to salt stress. J. Plant Physiol. 156: 335-340, 2000.

Palma F., Lluch C., Iribarne C. et al.: Combined effect of salicylic acid and salinity on some antioxidant activities, oxidative stress and metabolite accumulation in Phaseolus vulgaris. Plant Growth Regul. 58: 307-316, 2009.

Pan C.C., Liu C.A., Zhao H.L., Wang Y.: Changes of soil physico-chemical properties and enzyme activities in relation to grassland salinization. - Eur. J. Soil Biol. 55: 13-19, 2013.

Panda A., Rangani J., Parida A.K.: Cross talk between ROS homeostasis and antioxidative machinery contributes to salt tolerance of the xero-halophyte Haloxylon salicornicum. Environ. Exp. Bot. 166: 103799, 2019.

Pandey D.M., Choi I., Yeo U.-D.: Photosystem 2-activity and thylakoid membrane polypeptides of in vitro cultured chrysanthemum as affected by $\mathrm{NaCl}$. - Biol. Plantarum 53: 329-333, 2009.

Pandey D.M., Kang K.-H., Yeo U.-D.: Effects of excessive photon on the photosynthetic pigments and violaxanthin de-epoxidase activity in the xanthophyll cycle of spinach leaf. - Plant Sci. 168: 161-166, 2005.

Parida A.K., Veerabathini S.K., Kumari A., Agarwal P.K.: Physiological, anatomical and metabolic implications of salt tolerance in the halophyte Salvadora persica under 
hydroponic culture condition. - Front. Plant Sci. 7: 351, 2016.

Rajhi I., Ben Moussa S., Neji I. et al.: Photosynthetic and physiological responses of small seeded faba bean genotypes (Vicia faba L.) to salinity stress: identification of a contrasting pair towards salinity. - Photosynthetica 58: 174-185, 2020.

Rattan A., Kapoor D., Kapoor N. et al.: Brassinosteroids regulate functional components of antioxidative defense system in salt stressed maize seedlings. - J. Plant Growth Regul. 39: 14651475, 2020.

Reddy M.P., Vora A.B.: Changes in pigment composition, Hill reaction activity and saccharides metabolism in bajra (Pennisetum typhoides $\mathrm{S} \& \mathrm{H}$ ) leaves under $\mathrm{NaCl}$ salinity. Photosynthetica 20: 50-55, 1986.

Sehar Z., Masood A., Khan N.A.: Nitric oxide reverses glucosemediated photosynthetic repression in wheat (Triticum aestivum L.) under salt stress. - Environ. Exp. Bot. 161: 277289, 2019.

Sergiev I., Alexieva V., Karanov E.: Effect of spermine, atrazine and combination between them on some endogenous protective systems and stress markers in plants. - Compt. Rend. Acad. Bulg. Sci. 51: 121-124, 1997.

Shabala S., Mackay A.: Ion transport in halophytes. - Adv. Bot. Res. 57: 151-199, 2011.

Shafeiee M., Ehsanzadeh P.: Physiological and biochemical mechanisms of salinity tolerance in several fennel genotypes: Existence of clearly-expressed genotypic variations. - Ind. Crop. Prod. 132: 311-318, 2019.

Shahbaz M., Zia B.: Does exogenous application of glycinebetaine through rooting medium alter rice (Oryza sativa L.) mineral nutrient status under saline conditions? - J. Appl. Bot. Food Qual. 84: 54-60, 2011.

Shi Y., Wang Z., Lui C., Yang Z.: [Glacial resources of the arid regions in Northwest China and their utilization.] - In: Zhao S. (ed.): [Utilization and Development of Natural Resources in Arid and Semi-Arid Lands.] Pp. 26-32. Science Press, Beijing 1989. [In Chinese]

Sibole J.V., Cabot C., Poschenrieder C., Barceló J.: Efficient leaf ion partitioning, an overriding condition for abscisic acidcontrolled stomatal and leaf growth responses to $\mathrm{NaCl}$ salinization in two legumes. - J. Exp. Bot. 54: 2111-2119, 2003.
Singh M., Kumar J., Singh S. et al.: Roles of osmoprotectants in improving salinity and drought tolerance in plants: a review. Rev. Environ. Sci. Biotechnol. 14: 407-426, 2015.

Singh M., Kumar J., Singh V.P., Prasad S.M.: Plant tolerance mechanism against salt stress: the nutrient management approach. - Biochem. Pharmacol. 3: 165, 2014.

Smart R.E., Bingham G.E.: Rapid estimates of relative water content. - Plant Physiol. 53: 258-260, 1974.

Sofy M.R., Elhawat N., Alshaal T.: Glycine betaine counters salinity stress by maintaining high $\mathrm{K}^{+} / \mathrm{Na}^{+}$ratio and antioxidant defense via limiting $\mathrm{Na}^{+}$uptake in common bean (Phaseolus vulgaris L.). - Ecotox. Environ. Safe. 200: 110732, 2020.

Ungar I.A.: Ecophysiology of Vascular Halophytes. Pp. 221. CRC Press, Boca Raton 1991.

Veatch-Blohm M.E., Malinowski M., Keefer D.: Leaf water status, osmotic adjustment and carbon assimilation in colored calla lilies in response to saline irrigation. - Sci. Hortic.Amsterdam 144: 65-73, 2012.

Verslues P.E., Agarwal M., Katiyar-Agarwal S. et al.: Methods and concepts in quantifying resistance to drought, salt and freezing, abiotic stress that affect plant water status. - Plant J. 45: 523-539, 2006.

Wang J.C., Meng Y.X., Li B.C. et al.: Physiological and proteomic analyses of salt stress response in the halophyte Halogeton glomeratus. - Plant Cell Environ. 38: 655-669, 2015.

Wang R., Chen S., Zhou X. et al.: Ionic homeostasis and reactive oxygen species control in leaves and xylem sap of two poplars subjected to $\mathrm{NaCl}$ stress. - Tree Physiol. 28: 947-957, 2008.

Weckx J.E.J., Clijsters H.M.M.: Oxidative damage and defense mechanisms in primary leaves of Phaseolus vulgaris as a result of root assimilation of toxic amounts of copper. Physiol. Plantarum 96: 506-512, 1996.

Zeng F.J., Bleby T.M., Landman P.A. et al.: Water and nutrient dynamics in surface roots and soils are not modified by shortterm flooding of phreatophytic plants in a hyperarid desert. Plant Soil 279: 129-139, 2006.

Zhu Y.F., Wu Y.X., Hu Y. et al.: Tolerance of two apple rootstocks to short-term stress: focus on chlorophyll degradation, photosynthesis, hormone and leaf ultrastructures. - Acta Physiol. Plant. 41: 87, 2019.

(C) The authors. This is an open access article distributed under the terms of the Creative Commons BY-NC-ND Licence. 